\title{
Docetaxel plus cisplatin is effective for patients with metastatic breast cancer resistant to previous anthracycline treatment: a phase II clinical trial
}

\author{
Se Hoon Park ${ }^{1}$, Eun Kyung Cho ${ }^{1}$, Soo-Mee Bang1, Dong Bok Shin*1, \\ Jae Hoon Lee ${ }^{1}$ and Young Don Lee ${ }^{2}$
}

\author{
Address: ${ }^{1}$ Division of Hematology and Oncology, Internal Medicine, Gachon Medical School Gil Medical Center, Incheon 405-760, Korea and \\ 2Department of Breast Surgery, Gachon Medical School Gil Medical Center, Incheon 405-760, Korea \\ Email: Se Hoon Park - hematoma@ghil.com; Eun Kyung Cho - ekcho@ghil.com; Soo-Mee Bang - smbang@ghil.com; \\ Dong Bok Shin* - dbs@ghil.com; Jae Hoon Lee - jhlee@ghil.com; Young Don Lee - peacemk@ghil.com \\ * Corresponding author
}

Published: 22 February 2005

BMC Cancer 2005, 5:2I doi:10.1|86/147|-2407-5-2|

This article is available from: http://www.biomedcentral.com/I47/-2407/5/2 I

(c) 2005 Park et al; licensee BioMed Central Ltd.

This is an Open Access article distributed under the terms of the Creative Commons Attribution License (http://creativecommons.org/licenses/by/2.0), which permits unrestricted use, distribution, and reproduction in any medium, provided the original work is properly cited.

\begin{abstract}
Background: Patients with metastatic breast cancer (MBC) are frequently exposed to high cumulative doses of anthracyclines and are at risk of resistance and cardiotoxicity. This phase II trial evaluated the efficacy and toxicity of docetaxel plus cisplatin, as salvage chemotherapy in patients with $M B C$ resistant to prior anthracyclines.
\end{abstract}

Methods: Patients with MBC that had progressed after at least one prior chemotherapy regimen containing anthracyclines received docetaxel $75 \mathrm{mg} / \mathrm{m}^{2}$ followed by cisplatin $60 \mathrm{mg} / \mathrm{m}^{2}$ every 3 weeks for a maximum of 6 cycles or until disease progression.

Results: Between Jan 2000 and May 2002, 24 patients with tumors primary resistant and 15 with secondary resistant disease were accrued. All 39 patients were evaluable for safety and 36 for efficacy. The objective response rate was $31 \%(95 \% \mathrm{Cl}, 16-45 \%)$ with 3 complete responses. The median time to disease progression was 7 months, and the median overall survival was 23 months (median follow-up of 41 months). Neutropenia was the most frequently observed severe hematologic toxicity ( $39 \%$ of patients), whereas asthenia and nausea were the most common nonhematologic toxicities. No treatment-related death was observed.

Conclusion: In conclusion, we found docetaxel plus cisplatin to be an active and safe chemotherapy regimen for patients with MBC resistant to anthracyclines.

\section{Background}

In the management of breast cancer, anthracycline-based chemotherapy regimens remain standard adjuvant or first-line palliative treatment. Furthermore, some patients cannot be treated with anthracyclines due to impaired cardiac function. It is thus important to identify active, well- tolerated, not anthracycline cross-resistant, salvage regimens [1].

Taxanes (docetaxel and paclitaxel) are currently the most extensively studied new chemotherapeutic agents for metastatic breast cancer (MBC). Single-agent docetaxel has 
demonstrated significant survival advantages over other recognized regimens in 2 large randomized trials in patients with anthracycline-pretreated MBC [2,3]. Phase II data suggest that docetaxel is the most active agent yet available for the treatment of MBC [4]. Docetaxel also has some activity in paclitaxel-resistant MBC [5].

Cisplatin monotherapy has shown response rate of $9 \%$ in salvage settings, and $50 \%$ as first-line therapy [6]. Because docetaxel and cisplatin are both active and have different mechanisms of action, this combination may provide additive effect against MBC. Although docetaxel and cisplatin were not actively synergistic in preclinical studies $[7,8]$, this combination chemotherapy has been widely used for treatment of a variety of tumor types [9-13]. Prior phase I studies showed the feasibility of this combination and its activity on different tumors [14]. Considering the single-agent activity of both drugs, their different mechanism of action and distinct toxicity profile, we designed this phase II study, in which the combination was evaluated as a salvage therapy in patients with anthracyclineresistant MBC.

\section{Methods \\ Eligibility}

Eligible patients had measurable or assessable histologically confirmed breast cancer that had progressed after at least one prior chemotherapy regimen containing anthracyclines. All patients had Eastern Cooperative Oncology Group performance status of 2 or lower and adequate bone marrow, hepatic, and renal function, defined as white blood cells $\geq 4000 / \mu \mathrm{L}$, absolute neutrophil count $\geq 1500 / \mu \mathrm{L}$, platelets $\geq 100,000 / \mu \mathrm{L}$, total bilirubin $\leq 2.0 \mathrm{mg} /$ $\mathrm{dL}$, transaminases $\leq 3$ times the upper normal limit, and serum creatinine $\leq 1.5 \mathrm{mg} / \mathrm{dL}$. Concurrent radiation or hormonal therapy was not allowed; however, patients with clinically stable metastases of the brain or other sites who had completed radiation therapy were permitted. Patients were eligible regardless of the nature of prior therapy, including high-dose therapy with stem cell support and prior exposure to paclitaxel. Any prior antitumor treatment had been completed at least 1 month before entering this study. Patients were excluded if they had severe comorbid illness, symptomatic peripheral neuropathy of any origin, or a history of anaphylaxis of any type. All patients were provided a thorough explanation of the study, and they signed informed consent prior to enrollment into the study.

\section{Definition of anthracycline-resistance}

Patients were classified as primary and secondary anthracycline-resistant. Primary anthracycline-resistance was defined as relapse during or within 12 months after anthracycline-based adjuvant therapy, or disease progression with no intervening response during anthracycline- containing chemotherapy for MBC. Secondary resistance was defined as relapse more than 12 months after receiving adjuvant anthracycline chemotherapy, or disease progression at some time after a documented clinical response to anthracycline-based chemotherapy for MBC.

\section{Pretreatment and follow-up evaluation}

Pretreatment evaluation included a complete medical history and physical examination, a computed tomographic (CT) scan of the chest and abdomen, magnetic resonance imaging (MRI) of the brain, and a bone scintigraphy to assess the extent of disease. Follow-up consisted of physical examination, monitoring of toxic effects, a complete blood count, liver function tests, chest radiography, and CT scan as clinically indicated.

Tumor response and toxicity were recorded in accordance with the World Health Organization (WHO) criteria. Responses were assessed every 2 cycles of chemotherapy, and patients were evaluated before each new treatment cycle for toxicities.

\section{Treatment plan}

The treatment consisted of docetaxel (Taxotere ${ }^{\varpi}$, Aventis, Bridgewater, NJ) $75 \mathrm{mg} / \mathrm{m}^{2}$ given by a 1 -hour intravenous infusion immediately followed by cisplatin $60 \mathrm{mg} / \mathrm{m}^{2}$ in a 2-hour infusion. Cycles were repeated every 3 weeks if the patient's blood count had returned to normal and non-hematologic toxicities had resolved. Dosage of subsequent cycles was adjusted according to the observed toxicities that developed during the preceding cycle. The treatment continued for a maximum of 6 cycles or until disease progression. All patients received standard supportive care regimen consisting of adequate hydration, dexamethasone, and antiemetic therapy according to the guidelines of the American Society of Clinical Oncology [15].

\section{Statistics}

The primary end points of the trial were the efficacy of the therapy, which were measured as objective response rate and time to progression, with a secondary end point of toxicity. All patients who received at least 2 cycles of treatment or who progressed after the first cycle were considered assessable for response. The study was conducted using a single-stage, phase II trial design [16]. Based on the results from previous phase II trials reporting response rates of about $30 \%$ in patients with anthracycline-resistant $\mathrm{MBC}$, we selected a $50 \%$ target response probability and a $30 \%$ null response probability, with type I and type II error set at $10 \%$. The number of patients required was 39 .

Statistical calculations were performed using SPSS software, version 11.5 (SPSS, Inc, Chicago, IL). Comparisons were performed using chi-square test and survival curves 
Table I: Patient characteristics

\begin{tabular}{|c|c|c|}
\hline & No. & $\%$ \\
\hline \multicolumn{3}{|l|}{ Patients } \\
\hline Treated & 39 & 100.0 \\
\hline Evaluable for response & 36 & 92.3 \\
\hline \multicolumn{3}{|l|}{ Age } \\
\hline Median (years) & 51.3 & \\
\hline Range & $4 I .2-64.1$ & \\
\hline \multicolumn{3}{|l|}{ ECOG performance status } \\
\hline 0 & 3 & 7.7 \\
\hline 1 & 27 & 69.2 \\
\hline 2 & 9 & 23.1 \\
\hline \multicolumn{3}{|l|}{ Site(s) of metastatic lesion(s)* } \\
\hline Lung & 27 & 69.2 \\
\hline Liver & 9 & 23.1 \\
\hline Lymph node & 15 & 38.5 \\
\hline Soft tissue & 3 & 7.7 \\
\hline Bone & 24 & 61.5 \\
\hline Brain & 3 & 7.7 \\
\hline \multicolumn{3}{|l|}{ Response to prior anthracyclines } \\
\hline Primary resistant & 24 & 61.5 \\
\hline Secondary resistant & 15 & 38.5 \\
\hline \multicolumn{3}{|l|}{ Interval from the cessation of last chemotherapy } \\
\hline Median (months) & 4.1 & \\
\hline Range & $1.0-11.2$ & \\
\hline \multicolumn{3}{|l|}{ No. of prior chemotherapy regimens } \\
\hline Hormonal therapy (total) & 20 & 51.3 \\
\hline I & 9 & 23.1 \\
\hline 2 & 21 & 53.8 \\
\hline 3 or more & 9 & 23.1 \\
\hline \multicolumn{3}{|l|}{ Characteristics of prior chemotherapy $\dagger$} \\
\hline CMF & 24 & \\
\hline CAF & 15 & \\
\hline FEC & 9 & \\
\hline VE & 21 & \\
\hline High-dose therapy with stem cell rescue & 6 & \\
\hline AT & 3 & \\
\hline
\end{tabular}

* Because patients could have metastases at multiple sites, the total numbers of metastases are greater than the number of patients. † CMF, cyclophosphamide $600 \mathrm{mg} / \mathrm{m}^{2}$, methotrexate $40 \mathrm{mg} / \mathrm{m}^{2}, 5$ fluorouracil $600 \mathrm{mg} / \mathrm{m}^{2}$, days I \& 8, every 4 weeks; CAF, cyclophosphamide $500 \mathrm{mg} / \mathrm{m}^{2}$, doxorubicin $50 \mathrm{mg} / \mathrm{m}^{2}, 5$-fluorouracil $500 \mathrm{mg} / \mathrm{m}^{2}$, every 3 weeks; FEC, 5 -fluorouracil $600 \mathrm{mg} / \mathrm{m}^{2}$, epirubicin $60 \mathrm{mg} / \mathrm{m}^{2}$, cyclophosphamide $600 \mathrm{mg} / \mathrm{m}^{2}$, every 4 weeks; VE, vinorelbine $25 \mathrm{mg} / \mathrm{m}^{2}$, days I \& 8, epirubicin $60 \mathrm{mg} / \mathrm{m}^{2}$ day I, every 3 weeks; AT, doxorubicin $50 \mathrm{mg} / \mathrm{m}^{2}$, paclitaxel $175 \mathrm{mg} / \mathrm{m}^{2}$, every 3 weeks.

were generated using Kaplan-Meier method. Results were considered significant at the $\mathrm{P}=.05$.

\section{Results}

\section{Patients characteristics}

Between Jan 2000 and May 2002, 24 patients with tumors primary resistant and 15 with secondary resistant disease were accrued. Among 39 patients assessable for safety, 3 were not evaluable for response due to early discontinuation of treatment.

Baseline characteristics of the eligible patients are listed in Table 1. Median age was 51 years (range, 41-64) and median performance status was 1 . Thirty-three patients $(85 \%)$ had visceral metastases as the dominant site of disease. All patients had received prior anthracycline-based chemotherapy with a median number of prior chemotherapeutic regimens of 2 (range, 1-3). Three patients $(8 \%)$ had exposed to paclitaxel in their previous chemotherapy regimen.

\section{Efficacy}

According to the "intent-to-treat" analysis, the objective response rate was 31\% (95\% confidence interval [CI], 16$45 \%)$. There were 3 complete responses, 12 partial responses and 15 patients had stable disease. The three patients who obtained a complete response had non-visceral metastatic pattern (neck lymph nodes and/or soft tissue lesions). Most patients who achieved a response did so at the end of the third cycle (median time to response, 2.2 months; 95\% CI, 2.1-2.4 months).

At a median follow-up of 40.5 months (95\% CI, 36.444.6 months), the median time to progression was 6.6 months (95\% CI, 3.9-9.4 months) and the median overall survival was 22.9 months (95\% CI, 17.2-28.5 months). The time to progression in responders were 16.7 months $(P<0.0001)$. The Kaplan-Meier method was used to estimate overall survival and time to progression, as shown in Figure 1. At the time of present analyses, 21 patients (54\%) died.

We observed no significant differences in overall response rate or survival between primary and secondary anthracycline-resistant groups. The overall survival and time to progression were higher in patients with objective response $(P<0.0001$ and $P=0.05$, respectively).

\section{Toxicity}

Patients received a median of 6 cycles (range, 1-6) of docetaxel plus cisplatin. Relative dose intensities were 84\% (95\% CI, 73-96\%) and 86\% (95\% CI, 75-97\%) for docetaxel and cisplatin, respectively. Twenty-four patients (62\%) completed 6 cycles of chemotherapy as planned; Nine patients had progression of disease while receiving treatment and 6 patients discontinued treatment because of toxicity. Treatment delay was occurred in 54 cycles $(29 \%)$.

Toxicity was evaluable in all 39 patients and 189 chemotherapy cycles. Even if the most frequent hematological toxicity was neutropenia (grade $3 / 4$ in $22 \%$ of treatment cycles), only 12 episodes of non-fatal febrile neutropenia 


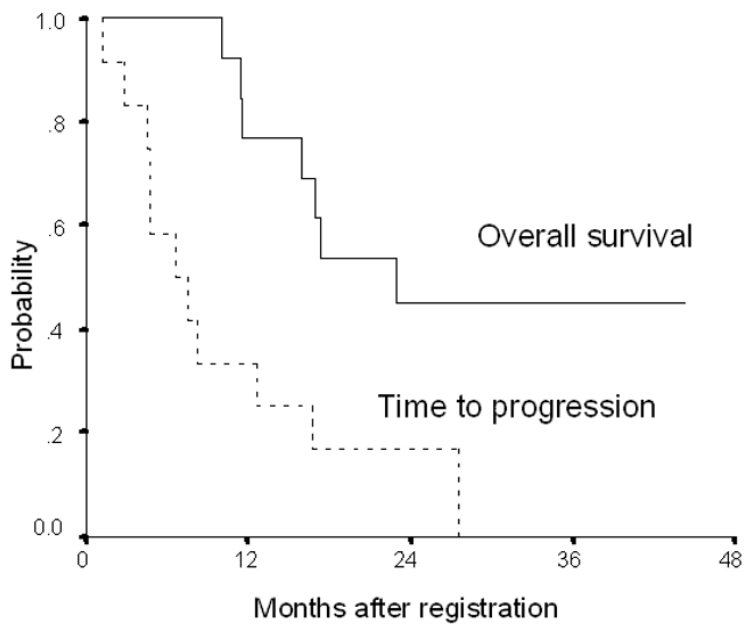

\section{Figure I}

Estimated curves of overall survival and time to progression. At a median follow-up of 40.5 months $(95 \% \mathrm{Cl}$, 36.4-44.6 months), the median time to progression was 6.6 months ( $95 \% \mathrm{Cl}, 3.9-9.4$ months) and the median overall survival was 22.9 months ( $95 \% \mathrm{Cl}, 17.2-28.5$ months).

were observed. The most commonly encountered nonhematologic toxicities were asthenia and nausea. Other toxicities are reported per patient and per cycle in Table 2. Six patients had severe toxicity precluding further treatment. No treatment-related deaths were observed.

\section{Discussion}

Single-agent docetaxel has been considered a standard treatment for patients with anthracycline-pretreated MBC for several years. Docetaxel monotherapy often demonstrated response rates of $50 \%$ or more in this setting $[17,18]$. Ahn et al. also reported, in a similar patient population, 36\% response rate and 69 weeks median survival with docetaxel $75 \mathrm{mg} / \mathrm{m}^{2}$ every 3 weeks[19].

Platinum-based combinations also have significant activity in previously treated as well as previously untreated patients. In several small clinical trials testing the cisplatin-based regimens, response rates of $50 \%-83 \%$ were reported [20]. The North Central Cancer Treatment Group (NCCTG) evaluated carboplatin combined with paclitaxel as first-line chemotherapy for MBC [21]. The overall response rate was $62 \%$ and the median time to progression was 7.3 months. Clearly, platinum-based combinations are very active against $\mathrm{MBC}$, but the relative degree of toxicity compared with other agents limited their use in routine clinical practice. Recently, synergism between platinum and trastuzumab, a novel monoclonal antibody directed against the protein product of the HER2/neu oncogene, awaked interest in the use of cisplatin for breast cancer $[6,22]$.

There are relatively few completed clinical studies involving platinum-based combination chemotherapy for anthracycline-resistant MBC. Spielmann et al. evaluated docetaxel $75 \mathrm{mg} / \mathrm{m}^{2}$ plus cisplatin $80 \mathrm{mg} / \mathrm{m}^{2}$ every 3 weeks in 38 patients with anthracycline-resistant $\mathrm{MBC}$, giving an objective response rate of $36 \%$ [23]. Japanese investigators performed a phase II study of docetaxel 60 $\mathrm{mg} / \mathrm{m}^{2}$ and cisplatin $80 \mathrm{mg} / \mathrm{m}^{2}$ in patients with anthracycline-pretreated MBC [24]. They reported an overall response rate of $64 \%$. In a phase II study of docetaxel and carboplatin, overall response rate of $61 \%$ was achieved in patients with chemotherapy-pretreated MBC [25]. Gelmon et al. combined biweekly paclitaxel with cisplatin and achieved a response rate of $85 \%$ with few septic events [26].

We classified "anthracycline-resistant" into primary and secondary. Ando et al. suggested that the status of anthracycline-resistance is important for the prediction of response to second-line treatment with docetaxel [27]. However, we could not observe significant difference in the efficacy of docetaxel plus cisplatin between primary and secondary resistant groups. The different outcomes might be due to the current situation that there have been no standard criteria defining anthracycline-resistance and often intermingled with "anthracycline-pretreated" or "anthracycline-refractory."

This study demonstrated that a combination of docetaxel plus cisplatin in a 3-week cycle was an effective and welltolerated regimen for patients with anthracycline-resistant MBC. In this study, the use of docetaxel plus cisplatin resulted in an overall response rate of $31 \%$ and the median time to progression was 7 months. Significant improvements in the actuarial survival rate and time to progression were observed in the group of patients who achieved objective responses. The main toxicities, gastrointestinal, hematological and asthenia, were manageable with dose adjustment and supportive care. Dose intensities of more than $80 \%$ were delivered and $61 \%$ of patients completed 6 cycles of chemotherapy, which is considered acceptable and expected. We used the planned dose of cisplatin $60 \mathrm{mg} / \mathrm{m}^{2}$ every 3 weeks, rather than 75 $\mathrm{mg} / \mathrm{m}^{2}$ cited in a phase I study [14], because we believed that tolerability of treatment is indispensable in the salvage setting in the management of solid tumors.

With the increasing use of anthracycline-based chemotherapy as adjuvant treatment, as well as first-line chemotherapy against $\mathrm{MBC}$, patients are frequently exposed to high cumulative doses of anthracyclines and are therefore 
Table 2: Toxicity of chemotherapy*

\begin{tabular}{lcccc}
\hline & \multicolumn{3}{c}{ Grade 1,2 } & Grade 3,4 \\
\cline { 2 - 4 } & / 39 pts & / I89 cycles & / 39 pts & / I89 cycles \\
\hline Febrile neutropenia & & & $12(31 \%)$ & $12(22 \%)$ \\
Neutropenia & $18(46 \%)$ & $28(15 \%)$ & $15(39 \%)$ & $42(22 \%)$ \\
Thrombocytopenia & $18(46 \%)$ & $24(13 \%)$ & $6(15 \%)$ & $9(5 \%)$ \\
Nausea/vomiting & $27(69 \%)$ & $42(22 \%)$ & $24(62 \%)$ & $32(22 \%)$ \\
Oral mucositis & $4(10 \%)$ & $5(3 \%)$ & $3(8 \%)$ & $24(13 \%)$ \\
Asthenia & $12(31 \%)$ & $12(22 \%)$ & $15(39 \%)$ & $9(5 \%)$ \\
Peripheral neuropathy & $6(15 \%)$ & $7(4 \%)$ & $6(15 \%)$ & \\
Hearing impairment & $3(8 \%)$ & $3(2 \%)$ & & \\
Renal insufficiency & $1(3 \%)$ & $1(1 \%)$ & & \\
\hline
\end{tabular}

* Others: abdominal pain(I), skin rash(I), fatigue(6)

at risk of resistance and cardiotoxicity [28]. This combination of docetaxel with cisplatin may be particularly useful in patients previously treated with anthracyclines (but naïve to either docetaxel or cisplatin). In addition, for patients who have already had cardiac failure and have not received chemotherapy with taxanes as an adjuvant or as first-line treatment, use of docetaxel plus cisplatin is considered a better option. More recently, reports that trastuzumab has a powerful synergistic interaction with docetaxel and with cisplatin [29], have prompted evaluation of the combination of trastuzumab with docetaxel and/or platinum in the treatment of MBC $[30,31]$.

\section{Conclusion}

In summary, the combination of docetaxel plus cisplatin is active and safe in patients with anthracycline-resistant MBC. The activity observed in anthracycline-resistant and heavily-pretreated patients suggests relative non-crossresistance with other drug combinations. Therefore, we hope that this study could result in a prospective trial to determine whether this activity translates into actual improvement in survival and quality of life in patients with anthracycline-resistant MBC.

\section{Competing interests}

The author(s) declare that they have no competing interests.

\section{Authors' contributions}

SHP collected the data, performed the statistical analysis and drafted the manuscript. EKC, SB, JHL, YDL followed the patients. DBS designed the study, followed the patients and helped with the manuscript. All authors read and approved the final manuscript.

\section{References}

I. O'Shaughnessy J, Twelves C, Aapro M: Treatment for anthracycline-pretreated metastatic breast cancer. Oncologist 2002, 7(Suppl 6):4-12.

2. Nabholtz JM, Senn HJ, Bezwoda WR, Melnychuk D, Deschenes L, Douma J, Vandenberg TA, Rapoport B, Rosso R, Trillet-Lenoir V, Drbal J, Molino A, Nortier JW, Richel DJ, Nagykalnai T, Siedlecki P, Wilking N, Genot JY, Hupperets PS, Pannuti F, Skarlos D, Tomiak EM, Murawsky M, Alakl M, Aapro M, 304 Study Group: Prospective randomized trial of docetaxel versus mitomycin plus vinblastine in patients with metastatic breast cancer progressing despite previous anthracycline-containing chemotherapy. J Clin Oncol 1999, I7(5): |413-1424.

3. Sjostrom J, Blomqvist C, Mouridsen H, Pluzanska A, Ottosson-Lonn S, Bengtsson NO, Ostenstad B, Mjaaland I, Palm-Sjovall M, Wist E, Valvere $V$, Anderson $H$, Bergh J: Docetaxel compared with sequential methotrexate and 5-fluorouracil in patients with advanced breast cancer after anthracycline failure: a randomised phase III study with crossover on progression by the Scandinavian Breast Group. Eur J Cancer 1999, 35(8): I I 94- I 201.

4. Crown J: A review of the efficacy and safety of docetaxel as monotherapy in metastatic breast cancer. Semin Oncol 1999, 26(I Suppl 3):5-9.

5. Valero V, Jones SE, Von Hoff DD, Booser DJ, Mennel RG, Ravdin PM, Holmes FA, Rahman Z, Schottstaedt MW, Erban JK, Esparza-Guerra L, Earhart RH, Hortobagyi GN, Burris HA 3rd: A phase II study of docetaxel in patients with paclitaxel-resistant metastatic breast cancer. J Clin Oncol 1998, 16(10):3362-3368.

6. Crown J: The platinum agents: a role in breast cancer treatment? Semin Oncol 200I, 28(I Suppl 3):28-37.

7. Bissery MC, Nohynek G, Sanderink GJ, Lavelle F: Docetaxel (Taxotere): a review of preclinical and clinical experience. Part I: Preclinical experience. Anticancer Drugs 1995, 6(3):339-355. 363368

8. Aoe K, Kiura K, Ueoka H, Tabata M, Matsumura T, Chikamori M, Matsushita A, Kohara H, Harada M: Effect of docetaxel with cisplatin or vinorelbine on lung cancer cell lines. Anticancer Res 1999, I 9( I A):291-299.

9. Schoffski Schoffski P, Catimel G, Planting AS, Droz JP, Verweij J, Schrijvers D, Gras L, Schrijvers A, Wanders J, Hanauske AR: Docetaxel and cisplatin: an active regimen in patients with locally advanced, recurrent or metastatic squamous cell carcinoma of the head and neck. Results of a phase II study of the EORTC Early Clinical Studies Group. Ann Oncol 1999, I0(I): I19-122.

10. Le Chevalier T, Berille J, Zalcberg JR, Millward MJ, Monnier A, Douillard JY, McKeage MJ, James R, Soulas F, Loret C, Bougon N, Bizzari JP: Overview of docetaxel (Taxotere)/cisplatin combination in non-small cell lung cancer. Semin Oncol 1999, 26(3 Suppl II):I3-18. 
11. Roth AD, Maibach R, Martinelli G, Fazio N, Aapro MS, Pagani O, Morant R, Borner MM, Herrmann R, Honegger H, Cavalli F, Alberto $P$, Castiglione M, Goldhirsch A: Docetaxel (Taxotere)-cisplatin (TC): an effective drug combination in gastric carcinoma. Swiss Group for Clinical Cancer Research (SAKK), and the European Institute of Oncology (EIO). Ann Oncol 2000, I I(3):30I-306.

12. PA, Paul J, Birt A, Junor EJ, Reed NS, Symonds RP, Atkinson R, Graham J, Crawford SM, Coleman R, Thomas H, Davis J, Eggleton SP, Kaye SB: Docetaxel and cisplatin in combination as first-line chemotherapy for advanced epithelial ovarian cancer. Scottish Gynaecological Cancer Trials Group. J Clin Oncol 1999, I7(7):2069-2080.

13. Dimopoulos MA, Bakoyannis C, Georgoulias V, Papadimitriou C, Moulopoulos LA, Deliveliotis C, Karayannis A, Varkarakis I, Aravantinos G, Zervas A, Pantazopoulos D, Fountzilas G, Bamias A, Kyriakakis Z, Anagnostopoulos A, Giannopoulos A, Kosmidis P: Docetaxel and cisplatin combination chemotherapy in advanced carcinoma of the urothelium: a multicenter phase II study of the Hellenic Cooperative Oncology Group. Ann Oncol 1999, I O(I I): I 385-I 388.

14. Pronk LC, Schellens JH, Planting AS, van den Bent MJ, Hilkens PH, van der Burg ME, de Boer-Dennert M, Ma J, Blanc C, Harteveld M, Bruno R, Stoter G, Verweij J: Phase I and pharmacologic study of docetaxel and cisplatin in patients with advanced solid tumors. J Clin Oncol 1997, 15(3): 107I-1079.

15. Gralla RJ, Osoba D, Kris MG, Kirkbride P, Hesketh PJ, Chinnery LW, Clark-Snow R, Gill DP, Groshen S, Grunberg S, Koeller JM, Morrow GR, Perez EA, Silber JH, Pfister DG: Recommendations for the use of antiemetics: evidence-based, clinical practice guidelines. American Society of Clinical Oncology. J Clin Oncol 1999, I 7(9):297|-2994.

16. Fleming TR: One-sample multiple testing procedure for phase II clinical trials. Biometrics 1982, 38(I):|43-|5I.

17. Ravdim PM, Burris HA 3rd, Cook G, Eisenberg P, Kane M, Bierman WA, Mortimer J, Genevois E, Bellet RE: Phase II trial of docetaxel in advanced anthracycline-resistant or anthracenedioneresistant breast cancer. J Clin Oncol 1995, I 3( I 2):2879-2885.

18. Valero V, Holmes FA, Walters RS, Theriault RL, Esparza L, Fraschini G, Fonseca GA, Bellet RE, Buzdar AU, Hortobagyi GN: Phase II trial of docetaxel: a new, highly effective antineoplastic agent in the management of patients with anthracycline-resistant metastatic breast cancer. I Clin Oncol I995, I 3( I 2):2886-2894.

19. Ahn JB, Shim KY, Park JO, Chung HC, Yoo NC, Chung HC, Kim JH, Choi JH, Kim HS, Kim HC, Kim WK, Roh JK: The Efficacy and Safety of Docetaxel in Patients with Anthracycline-pretreated Metastatic Breast Cancer: A Multicenter Phase II Study. J Korean Cancer Assoc 2000, 32(2):235-243.

20. Sledge GW Jr, Roth BJ: Cisplatin in the management of breast cancer. Semin Oncol 1989, 16(4 suppl 6): I 10-1 I5.

21. Perez EA, Hillman DW, Stella PJ, Krook JE, Hartmann LC, Fitch TR, Hatfield AK, Mailliard JA, Nair S, Kardinal CG, Ingle JN: A phase II study of paclitaxel plus carboplatin as first-line chemotherapy for women with metastatic breast carcinoma. Cancer 2000, 88(1):|24-|3|.

22. Naruse I, Fukumoto H, Saijo N, Nishio K: Enhanced anti-tumor effect of trastuzumab in combination with cisplatin. Jpn J Cancer Res 2002, 93(5):574-58I.

23. Spielmann M, Llombart A, Zelek L, Sverdlin R, Rixe O, Le Cesne A: Docetaxel-cisplatin combination (DC) chemotherapy in patients with anthracycline-resistant advanced breast cancer. Ann Oncol 1999, I0( I 2): |457-1460.

24. Kariya S, Ogawa Y, Nishioka A, Yoshida S: Docetaxel-cisplatin combined chemotherapy in Japanese patients with anthracycline-pretreated advanced breast cancer. Oncol Rep 2002, 9(6): $1345-1349$.

25. Mavroudis D, Alexopoulos A, Malamos N, Ardavanis A, Kandylis C, Stavrinidis E, Kouroussis Ch, Agelaki S, Androulakis N, Bozionelou V, Georgoulias V: Salvage treatment of metastatic breast cancer with docetaxel and carboplatin. A multicenter phase II trial. Oncology 2003, 64(3):207-2I2.

26. Gelmon KA, O'Reilly SE, Tolcher AW, Campbell C, Bryce C, Ragaz J, Coppin C, Plenderleith IH, Ayers D, McDermott B, Nakashima L, Healey D, Onetto N: Phase I/II trial of biweekly paclitaxel and cisplatin in the treatment of metastatic breast cancer. I Clin Oncol 1996, 14(4): II85-1191.
27. Ando M, Watanabe T, Nagata K, Narabayashi M, Adachi I, Katsumata $\mathrm{N}$ : Efficacy of docetaxel $60 \mathrm{mg} / \mathrm{m}^{2}$ in patients with metastatic breast cancer according to the status of anthracycline resistance. J Clin Oncol 200I, 19(2):336-342.

28. Wood WC, Budman DR, Korzun AH, Cooper MR, Younger J, Hart RD, Moore A, Ellerton JA, Norton L, Ferree CR, Ballow AC, Frei E, Henderson IC: Dose and dose intensity of adjuvant chemotherapy for stage II, node-positive breast carcinoma. $\mathrm{N} \mathrm{EnglJ}$ Med 1994, 330(18): 1253-1259.

29. Slamon DJ, Leyland-Jones B, Shak S, Fuchs H, Paton V, Bajamonde A Fleming T, Eiermann W, Wolter J, Pegram M, Baselga J, Norton L: Use of chemotherapy plus a monoclonal antibody against HER2 for metastatic breast cancer that overexpresses HER2. N Engl J Med 200I, 344( I I):783-792.

30. Brufsky AM, Cleary D, Fuchs C, Lebish J, Baar J, Evans T, Lembersky $B$, Belani CP: First-line chemotherapy for metastatic breast cancer (MBC) with docetaxel (T), carboplatin (C), and traztuzumab (H) (TCH): A phase II trial. Proc Am Soc Clin Oncol 2003, 22: I8. (abstr 7I)

31. Crown J, Pegram M: Platinum-taxane combinations in metastatic breast cancer: an evolving role in the era of molecularly targeted therapy. Breast Cancer Res Treat 2003, 79(Suppl I):SII-SI8.

\section{Pre-publication history}

The pre-publication history for this paper can be accessed here:

http://www.biomedcentral.com/1471-2407/5/21/prepub
Publish with Biomed Central and every scientist can read your work free of charge

"BioMed Central will be the most significant development for disseminating the results of biomedical research in our lifetime. "

Sir Paul Nurse, Cancer Research UK

Your research papers will be:

- available free of charge to the entire biomedical community

- peer reviewed and published immediately upon acceptance

- cited in PubMed and archived on PubMed Central

- yours - you keep the copyright

Submit your manuscript here:

http://www.biomedcentral.com/info/publishing_adv.asp
BioMedcentral 